LA W RENCE LIVERMORE N A TION AL LABORATORY

\section{Late-time simulation of National Ignition Facility Hohlraums}

D.C. Eder, O.S. Jones, M.M. Marinak, M.T. Tobin, B.J. MacGowan

September 21, 2004

Nuclear Fusion 2004 
This document was prepared as an account of work sponsored by an agency of the United States Government. Neither the United States Government nor the University of California nor any of their employees, makes any warranty, express or implied, or assumes any legal liability or responsibility for the accuracy, completeness, or usefulness of any information, apparatus, product, or process disclosed, or represents that its use would not infringe privately owned rights. Reference herein to any specific commercial product, process, or service by trade name, trademark, manufacturer, or otherwise, does not necessarily constitute or imply its endorsement, recommendation, or favoring by the United States Government or the University of California. The views and opinions of authors expressed herein do not necessarily state or reflect those of the United States Government or the University of California, and shall not be used for advertising or product endorsement purposes. 


\title{
Late-time simulation of National Ignition Facility hohlraums
}

\author{
D. C. Eder, A. E. Koniges, O. S. Jones, M. M. Marinak, M. T. Tobin, and \\ B. J. MacGowan
}

Lawrence Livermore National Laboratory, Livermore, CA 94551

\begin{abstract}
The late-time ( $\mathrm{t} \geq 80 \mathrm{~ns}$ ) behavior of hohlraums designed for the National Ignition Facility (NIF) is simulated using the multiphysics radiation hydrodynamics codes LASNEX and HYDRA. The spatial distribution of x-radiation outside the hohlraum is shown as a function of time. The energy spectrum of the x-ray emission is presented for various hohlraum viewing angles. We have made refinements to the grid motion algorithms in the arbitrary Lagrangian Eulerian (ALE) hydrodynamics code HYDRA to obtain the first late-time simulations of a hohlraum that can be used to give the spatial distribution of the vaporized hohlraum wall. The importance of late-time simulations in determining the lifetimes of debris shields on NIF is discussed.
\end{abstract}




\section{Introduction}

The indirect-drive approach to inertial confinement fusion (ICF) uses cylindrical hohlraums driven by lasers to demonstrate ignition and gain [1]. The late-time behavior of hohlraums is important in determining the lifetimes for debris shields on the National Ignition Facility (NIF). By "late-time" we mean significantly longer than the pulse length---up to 4, or more, times the pulse length. Late-time simulations of hohlraums are also needed for future inertial fusion energy reactor chambers. Substantial work has been done on 2D simulations of ICF hohlraums up to the time of capsule ignition and burn $[2,3]$. Recently, this work in "early-time" simulations (roughly of the same time length as the pulse) has been extended by 3D calculations that explore issues of drive uniformity [4]. However, most late-time simulations of hohlraums have been in only 1D and are used to study such issues as the partitioning of x-ray energy and the kinetic energy of the vaporized debris $[5,6]$. Given the aspect ratio of the hohlraums and the presence of laser entrance holes (LEH's) or heavy-ion converters, we know the $\mathrm{x}$ rays and debris will not be isotropic. Thus, late-time 2D and even 3D simulations should be performed. In this paper, we give results for the first fully 2D late-time simulations of NIF hohlraums.

For hohlraums heated by lasers, the high atomic number of wall material ensures that $70 \%$ to $80 \%$ of the laser energy is converted into $\mathrm{x}$ rays. However, the fraction of input energy that drives the capsule implosion is much less, $10 \%$ to $25 \%$. This difference is primarily due to three reasons: (1) radiation is escaping through the LEH's, (2) radiation is penetrating the walls (Marshak wave), and (3) a large ratio of wall area to capsule area is needed for drive symmetry [1-4]. Reducing the size of the LEH's improves coupling but causes the LEH's to close earlier, making it more difficult to get the laser energy into the hohlraum. Closure of the LEH to escaping $\mathrm{x}$ rays increases the kinetic energy of the vaporized wall material and increases the fraction of energy emitted 
as $\mathrm{x}$ rays from the wall. The duration of this wall $\mathrm{x}$-ray emission can be significantly longer than the laser pulse. When these $\mathrm{x}$ rays interact with diagnostic components, they can ablate or spall material.

NIF is a 192-beam, frequency-tripled $(\lambda=0.35 \mu \mathrm{m}), \mathrm{Nd}$ :glass laser system with an energy of 1.8 MJ in the ultraviolet (UV) and comparable energy entering the chamber as unconverted infrared light [7]. A similar laser facility, called the Laser Mega Joule (LMJ), is planned in France [8]. One difference between the two facilities is that unconverted light does not enter the LMJ chamber. The final optics for both NIF and LMJ are protected by a set of polished, fused silica debris shields about $1 \mathrm{~cm}$ thick. In order to extend the life of these main debris shields, thin (1- to 3-mm), disposable debris shields (DDS's) can be added to protect the main debris shields. The DDS's will be replaced after 1-10 shots depending on debris and shrapnel loading. We make the following distinction between debris and shrapnel: Debris is material deposited on the optic that does not damage the glass, whereas shrapnel has sufficient size and velocity to damage the optic. Shrapnel can be solid fragments or liquid droplets. For the standard indirect-drive configuration on NIF, the debris shields are clustered within approximately $50^{\circ}$ of the north and south poles of the chambers. No debris shields are placed in a band around the equator approximately $80^{\circ}$ wide. An understanding of this geometry allows us to define areas in the target chamber that can survive debris and shrapnel impact with no adverse affect on the optics, namely the equator region. However, there are diagnostic components in this equator region that require protection from debris and shrapnel. Thus to protect optics and diagnostics it is important to make the disassembly calculations in at least two dimensions.

The problem of debris and shrapnel characterization through modeling is a new area of research that will continue to grow in importance as NIF and other facilities come on line. Debris and shrapnel can be produced by the target material itself and also by diagnostic elements that are placed close enough to target center to be affected by x-ray 
emission and the target disassembly process. Because the thin DDS's cannot protect against shrapnel fragments that are both large and fast, we must control the number of such fragments striking the DDS's. A first and necessary step in predicting and controlling target debris and shrapnel is the development of late-time simulations that show what a given target/diagnostic configuration will produce. $\mathrm{X}$ rays from a target can produce debris and shrapnel in the surrounding diagnostic components. Thus, the spatial distribution of $\mathrm{x}$ rays from targets will influence the optimum location of diagnostic components. Finally, debris from the target may also affect the shrapnel fragments by pushing them in the direction of the expanding debris. In this paper, we give the first attempts to characterize the debris and $\mathrm{x}$ ray distribution in two-dimensions. This begins a program of research that should eventually, with improved computational resources and techniques, be able to simulate the entire disassembly process and the effects on surrounding diagnostics and structures.

For some late-time calculations, we use the 1D and 2D multiphysics radiation hydrodynamics code LASNEX [9,10]. In LASNEX hohlraum simulations, we often must rezone the mesh because shearing of the flow occurs when material leaves the inside walls of the hohlraum and exits the LEH's. The Lagrangian hydrodynamics in LASNEX can be run with user-controlled discrete rezoning or continuous rezoning, which can be equivalent to Eulerian hydrodynamics. Both rezoners use a Van Leer slope-limiting method that allows second-order remap accuracy in smooth regions, while not generating extraneous maxima/minima in the density at discontinuities.

For late-time calculations that include the outward expansion of the hohlraum wall, we use another ICF multiphysics radiation hydrodynamics code, called HYDRA [4]. The arbitrary Lagrangian Eulerian (ALE) hydrodynamics in HYDRA allow for a variety of algorithms to control grid motion continuously. We take advantage of this flexibility to allow the outer wall of the hohlraum to expand without significant mesh distortion. The simulations discussed in this paper are in 2D, but the $3 \mathrm{D}$ capability of 
HYDRA will be needed for hohlraums with nonaxial symmetric components, such as diagnostic windows or drive packages.

In Section II, we briefly describe modeling hohlraums with particular attention to the treatment of LEH's. In Section III, we discuss the results for the spatial distribution of $\mathrm{x}$ rays emitted from a NIF hohlraum, and in Section IV, we discuss the spatial distribution of material from the vaporized hohlraum wall. We present our conclusions in Section V.

\section{Hohlraum Modeling}

The primary benefit of indirect drive using hohlraums, compared with direct drive ICF, is the uniformity of the drive on the capsule. This improved uniformity greatly reduces the source term/seeding and growth of perturbations due to the Rayleigh-Taylor (RT) instability. However, indirect drive does increase energy losses through the wall and LEH's, it has a low coupling efficiency, and parametric instabilities may occur between an LEH and the wall. Indirect drive has been studied extensively using many different lasers [11-13] and underground nuclear explosives [14]. The primary focus of NIF is to demonstrate ignition and gain on the order of 10 using indirect drive. (Direct-drive experiments on NIF will be conducted in the future.) In this section, we briefly discuss modeling issues associated with hohlraums heated by lasers and what refinements are needed to simulate late-time effects.

The most common shape for laser-heated hohlraums is a cylinder with openings in the ends, i.e., LEH's. The radius of the LEH's is generally about one-half the radius of the hohlraum. The optimum size of the LEH depends on the spatial shape of the laser spot. Decreasing the size of the LEH reduces energy losses from the hohlraum but can make it more difficult to get all of the laser energy inside the hohlraum. Material ablated from the inside wall of the hohlraum changes the location of laser deposition during the pulse. Gas-filled hohlraums can be used to reduce this laser spot motion. To hold in the 
gas, windows (1- $\mu \mathrm{m}$-thick polyimid films) are placed over the LEH's. A potential gas mixture is equal amounts of $\mathrm{He}-\mathrm{H}$ at a density of about $1 \mathrm{mg} / \mathrm{cm}^{3}$. To reduce the amount of laser absorbing high- $Z$ wall material near the LEH's, plastic liners are added on top of the wall material near the LEH's.

We use late-time modeling to determine the spectral and spatial distribution of $\mathrm{x}$ rays outside the hohlraum. In contrast, the primary focus of hohlraum modeling for ICF ignition is to determine the $\mathrm{x}$-radiation drive on the capsule at the center of the hohlraum. The radiation leaving the hohlraum along with the spatial distribution of vaporized hohlraum material is important in determining how the target affects the remaining chamber components. Closure of the LEH's to laser light is important for ignition, while closure of the LEH's to $\mathrm{x}$ rays is important for debris and shrapnel generation. If $\mathrm{x}$ rays from the hot inside walls of the hohlraum cannot escape through the LEH's, the fraction of laser energy that goes into kinetic energy of debris increases. In addition, the x-ray emission from the outside of the hohlraum wall increases, which can affect diagnostic components exposed to this wall radiation.

\section{Late-Time X-Ray Spatial Distribution}

$\mathrm{X}$ rays emitted by hohlraums can ablate a significant amount of material from chamber components. In addition, shocks resulting from x-ray absorption can be strong enough to spall and fragment components that are close to the target center. Because of the LEH's and the aspect ratio of the hohlraums, the x-ray emission is not isotropic. Components that are exposed to the inside walls of the hohlraum through LEH's generally receive larger $\mathrm{x}$-ray fluences than components that are only exposed to outside wall emission. However, closure of the LEH to escaping $\mathrm{x}$ rays reduces the late-time cooling of hohlraums and increases the x-ray emission through the walls of the hohlraum.

Hohlraums of various sizes will be used on NIF, and the input laser energy will have a large variation. As an example, we give results for a NIF hohlraum with an input 
UV laser energy of $325 \mathrm{~kJ}$. In the final NIF configuration planned for several years in the future, 192 beams of NIF will be grouped into four clusters. A single one of these clusters with $325 \mathrm{~kJ}$ should be available in the near future. (Final operation will have 450 $\mathrm{kJ} /$ cluster giving a total UV energy of 1.8 MJ.) Initial "first cluster" hohlraum experiments will not contain a capsule, and thus that is what we are simulating in this paper. Even without a capsule, we must be sure the optics are protected from debris and shrapnel. The laser energy is sufficient to vaporize the entire target. The 1.0-scale hohlraum is $1.0 \mathrm{~cm}$ long and $0.6 \mathrm{~cm}$ in diameter with LEH's that are $0.3 \mathrm{~cm}$ in diameter. The wall of the gold hohlraum is $20 \mu \mathrm{m}$ thick. A diagram of the configuration is shown in Fig. 1 with the wall thickness not to scale. This simulation is for a "vacuum" hohlraum, i.e., no gas fill, plastic liners, or windows. An artificial cusp is added to the LEH in the simulation to allow fine zoning used along the inside wall of the hohlraum to continue at the LEH. (The effect of this cusp on the calculation of the hohlraum expansion is discussed in the next section.) We also show the three viewing angles $\left(0,45\right.$, and $\left.90^{\circ}\right)$, used in Figs. 4 and 6, which are repeated 2 or 4 times because of symmetry. The laser pulse shape is an "ignition type," consisting of a foot portion for $10 \mathrm{~ns}$ followed by rise to a peak intensity at approximately $15 \mathrm{~ns}$ with the laser shut off by $17 \mathrm{~ns}$. The pulse is shown in Fig. 2.

For this calculation of $\mathrm{x}$-ray emission, we use LASNEX. The 2D simulation is run to approximately $10 \mathrm{~ns}$ in Lagrangian mode with user-controlled discrete rezoning. The simulation is continued out to approximately $100 \mathrm{~ns}$ using continuous rezoning at each cycle to map back to a fixed mesh. The continuous rezoning part of the calculation is nearly equivalent to Eulerian hydrodynamics. Running the entire calculation in Lagrangian mode with discrete rezoning is very difficult because shear is associated with plasma leaving the LEH and plasma from the outside wall interacts with the ejected plasma. Although there is some loss of mass occurs at the edge of the mesh in Eulerian mode, this does not compromise the study of LEH closure to $\mathrm{x}$ rays. This simulation uses 
multigroup radiation diffusion and inline non-local thermodynamic equilibrium opacities. The total x-ray energy escaping from the hohlraum is calculated to be $222 \mathrm{~kJ}$ or $68 \%$ of the incoming laser energy. To determine what effect this radiation would have on surrounding diagnostics; it is necessary to know the spatial, temporal, and energy distribution of the emission.

The calculated x-ray emission (integrated over energy) from the hohlraum viewed at an angle of $45^{\circ}$ from the hohlraum axis is shown in Fig. 3 at 19.5 and 45.5 ns. At the earlier time, the hot interior wall of the hohlraum is clearly seen through the LEH and the exterior wall is also radiating significantly. At the latter time, the interior wall is no longer visible due to LEH closure and the exterior wall emission is less but bands showing location of laser beams are still visible. At the latter time, emission from material outside of the LEH is also visible. To create these images, as well as the results shown in Figs. 4-6, we store the opacity and emissivity for each zone as a function of energy and time. We use this information to solve the radiation transfer problem through the mesh in the direction given by the viewing angle.

The time dependence of the x-ray emission is shown in Fig. 4 for the same viewing angle used in Fig. $3\left(45^{\circ}\right)$ as well as on-axis viewing $\left(0^{\circ}\right)$ and perpendicular to the hohlraum axis $\left(90^{\circ}\right)$. The duration of the x-ray pulse is important in determining the response of a diagnostic to x-ray loading. A shorter duration can result in a larger shock in the component and increased probability of fragmentation and shrapnel generation. The interior wall of the hohlraum heated by the laser beams is the first region to emitted $\mathrm{x}$ rays (visible from $45^{\circ}$ ) with significant emission starting at around $11 \mathrm{~ns}$. The $\mathrm{x}$-ray emission viewed along the axis $\left(0^{\circ}\right)$ is delayed a few nanoseconds until plasma blows off from the walls. Both on-axis and 45-degree viewing have their maximum at about 15.5 ns, which is the peak of the laser pulse. The external wall of the hohlraum starts to radiate at about $13.5 \mathrm{~ns}$ and reaches its peak at about $17.5 \mathrm{~ns}$. For times greater than $20 \mathrm{~ns}$, the maximum of $\mathrm{x}$-ray emission is at $90^{\circ}$ because the largest area of the outside of the 
hohlraum is viewed from this angle. The wall emission has decreased to $10 \%$ of its maximum value $20 \mathrm{~ns}$ after the time of peak emission. The change in the slope at about $30 \mathrm{~ns}$ for the $\mathrm{x}$-ray emission along the axis $\left(0^{\circ}\right)$ occurs because of closure of the LEH to $\mathrm{x}$ rays from the interior of the hohlraum.

The spatial distribution of x-ray emission integrated over time in shown in Fig. 5. The minimum occurs along the axis $\left(0^{\circ}\right)$ because there is a clear view through the hohlraum and out the other LEH early in time. Plasma must ablate from the walls before there is significant emission from this angle. (If there was a capsule in the hohlraum, this would not be the case and one would expect a less pronounced minimum at $0^{\circ}$.) The maximum of $\mathrm{x}$-ray emission extends over a relatively broad range of angles from 15 to $55^{\circ}$. There is only a $30 \%$ drop in the $\mathrm{x}$-ray emission at $90^{\circ}$ compared to the maximum near $45^{\circ}$. This means that diagnostics components located along the waist of the hohlraum have only slightly smaller x-ray loading than those located with views of the LEH's. The response of the diagnostic components to x-ray loading also depends on the energy spectrum of the $\mathrm{x}$ rays.

In Fig. 6 we give the energy spectrum of the x-ray emission integrated over time for the same three angle used in Fig. $4\left(0,45\right.$, and $\left.90^{\circ}\right)$. We give the results in 10 energy bins extending out to $5 \mathrm{keV}$. We have normalized the three curves to make the difference with angle more transparent. The emission at $90^{\circ}$, which comes primarily from the exterior wall of the hohlraum, has the coldest spectrum with $88 \%$ of the emission from $\mathrm{x}$ rays having energies of $500 \mathrm{eV}$ and below. The percentages of emission in this energy range for 0 and $45^{\circ}$ viewing are 70 and $63 \%$, respectively. There is very little (2\%) high energy $(1-5 \mathrm{keV}) \mathrm{x}$-ray emission at $90^{\circ}$ with somewhat more at $0^{\circ}(8 \%)$ and $45^{\circ}(12 \%)$. For all angles the spectrum is hotter early in time (15-20 ns) and shifts to lower energy $\mathrm{x}$ rays as the hohlraum cools. The energy spectrum is important in determining how a diagnostic component is affected by the x-ray emission. For example, the threshold for $\mathrm{x}$ - 
ray ablation is significantly lower for less energetic $\mathrm{x}$ rays because the energy deposition is localized near the surface.

We have shown the spatial, temporal, and energy distribution of the x-ray emission for one particular hohlraum target at a given laser energy. The x-ray loading on diagnostics can vary significantly depends on target details (size, wall thickness, LEH radius, etc.), laser energy, pulse shape, and fusion yield. The response of diagnostics can include ablation, melting, and spalling/fragmentation. For components located $10 \mathrm{~cm}$ and more from the target's center, the major concern is the amount of ablated material from the component that is deposited on the debris shields [16]. For closer components, the relatively short duration and high fluence of the x-ray loading can drive a strong shock. When this shock reflects off a rear surface, it becomes a tensile wave and can be strong enough to cause components to spall or break up. The resulting shrapnel fragments can have sufficient velocity to damage debris shields. The trajectories of shrapnel fragments can be affected by the high velocity debris that sweeps past them from the vaporized target material.

\section{Late-Time Hohlraum Expansion}

The spatial distribution of vaporized hohlraum material is needed to determine its impact on the target chamber components, including the debris shields. Late-time simulations of hohlraums are difficult because of large shear flows through the LEH's and because the outer wall material interacts with plasma ejected earlier through the LEH's. One of the difficulties of late-time simulations is maintaining a mesh that is not severely distorted. The relatively thin hohlraum walls $(\sim 20 \mu \mathrm{m})$ compared to the hohlraum length $(\sim 1 \mathrm{~cm})$ leads to zones with initially large aspect ratios. This is enhanced by the need to resolve the laser deposition. In HYDRA, we use fine initial mesh spacing in the direction normal to the wall at the inner hohlraum surface. We find that an initial thickness of about $4 \mathrm{~nm}(40 \AA)$ is sufficient. However, for a $20-\mu \mathrm{m}$-thick wall, 
equal spacing of $4 \mathrm{~nm}$ would require 500 zones through the wall, which is an unacceptably large number. To have a tractable number of zones-say, 50 or so-we feather the zones, with thinner zones inside the hohlraum. The zone spacing along the hohlraum wall is about $100 \mu \mathrm{m}$, which corresponds to approximately 60 zones if half of the hohlraum is modeled because of symmetry. The aspect ratio of the zones on the inner wall is thus about 10,000 to 1 . These zones expand primarily in the direction normal to the surface, resulting in aspect ratios much closer to unity after ablation. To have adequate resolution on the portion of the hohlraum wall facing the LEH, we turn the mesh to form a cusp.

This artificial cusp that is added to simulations to obtain resolution at the LEH causes additional complications. To address these and related problems, we made various refinements in the ALE hydrodynamics in HYDRA. One significant refinement implemented into HYDRA is the ability to change how the code relaxes nodes near free boundaries. The relaxation algorithm tries to maintain $\mathbf{Q} \times(\mathbf{K} \cdot \mathbf{N})>0$, where $\mathbf{Q}$ is a HYDRA parameter, $\mathbf{K}$ is the local curvature vector on the outer boundary, and $\mathbf{N}$ is the unit normal to the surface. Setting $\mathbf{Q}$ negative causes the algorithm to reduce the amount of convex curvature. In this case, the mesh tends to be pulled back at each relaxation step, and some small amount of mass is lost during the advection step when the material is mapped to the new mesh. Setting $\mathbf{Q}$ positive causes the algorithm to reduce the amount of concave curvature. In this case, the mesh tends to be pulled out in places where curvature is concave. No mass is lost, in this case, because the old mesh is generally contained within the new mesh. However, resolution can be lost for a given object because the number of zones in that object is reduced to provide zones that can be pulled out. We show the effects of changing $\mathbf{Q}$ in the following example.

We calculate the expansion of a 0.6 -scale NIF gas-filled hohlraum with plastic liners adjacent to the LEH's and windows covering them. The energy is the same as that used in the above section ( $325 \mathrm{~kJ})$, but the hohlraum is $60 \%$ the size $(0.6$ scale) and the 
pulse duration is $60 \%$ as long as that used above. In Fig. 7, we show the evolution of the electron temperature in the hohlraum up to the time of maximum laser intensity at $8 \mathrm{~ns}$. This simulation has two symmetry planes, one at the equator and one running through the hohlraum axis. Thus we just show the top-right portion of the hohlraum. The inner and outer cone laser beams are clearly seen at $3 \mathrm{~ns}$. At $8 \mathrm{~ns}$, the plasma temperature inside the hohlraum is $300 \mathrm{eV}$ or hotter. The right-hand side of Fig. 7 shows enlarged views of the LEH region and the mesh for that area.

To maintain high resolution for the portion of wall that faces the axis at the LEH, we design the mesh to turn up, which creates a cusp — as clearly shown on the right-hand side of Fig. 7. However, with this design, the simulation may overestimate blowoff into the LEH because the width of the cusp is greater than the wall thickness. We are exploring this issue by using different radii of curvature for the cusp. At $8 \mathrm{~ns}$, plasma is coming around the top of the cusp, and after more time has elapsed, these zones would occupy the same space as the hohlraum wall above the LEH. Such an overlap introduces a general numerical problem that can happen even without a cusp. When zones on the outer boundary of a mesh curve around and attempt to occupy the same physical space as the outer zones at a different boundary location, they are not "aware" of each other. An explicit hydrodynamic algorithm communicates information locally during one cycle. Nodes on a free, vacuum Lagrangian mesh boundary do not communicate with nonadjacent boundary nodes. Thus care must be taken to avoid mesh collisions. We show how this can be done by varying the value of $\mathbf{Q}$ during the run.

We start the simulation with $\mathbf{Q}$ negative, which tends to hold back the mesh above the cusp and delays the time when the two parts of the mesh would collide. At a given time, which is problem dependent, the boundary relaxation is changed by setting $\mathbf{Q}$ positive. In this mode, the code attempts to relax the mesh to fill regions such as the one above the cusp in the right-hand side of Fig. 7 at 8 ns. When the mesh is relaxed, the 
material is left behind. The effectiveness of this approach depends on the resolution of the zoning. We switched relaxation mode in the simulation at around $10 \mathrm{~ns}$.

Figure 8 shows the electron temperature and mesh at 12, 20, and $30 \mathrm{~ns}$. The laser turns off at $11 \mathrm{~ns}$, and the electron temperature in the plasma inside the hohlraum at $12 \mathrm{~ns}$ is about $200 \mathrm{eV}$. On the right-hand side, we again show a blowup of the mesh around the LEH. At $12 \mathrm{~ns}$, the dip in the outer boundary above the cusp is largely removed because the mesh expanded/relaxed outward. The relatively cold hohlraum wall is still clearly seen. At $20 \mathrm{~ns}$, a region of higher temperature appears on axis because material is stagnating, and the concavity in the outer boundary above the LEH is completely eliminated. At $30 \mathrm{~ns}$, the temperature inside is nearly uniform again. The interaction of two different parts of the outer mesh boundary is avoided by relaxation of the mesh at the appropriate times and places. In general, the mesh boundary is not allowed to move faster than twice the plasma/fluid velocity of the material in the outer zones. However, during limited periods of time, we allow the mesh to move up to a factor of 10 faster than the fluid motion to permit rapid relaxation. By varying the ALE parameters in the simulation, we are able to demonstrate that there is not a significant loss of accuracy in the simulation using this technique. In effect, the simulation "builds its own mesh" to the accuracy required by the calculation.

To help visualize the hohlraum expansion, we give a time history of the different material boundaries in the hohlraum. First, in Fig. 9, we show an enlargement of the region around the left LEH. The thin polyimid window is green, the plastic liner of the wall near the LEH is blue, the gas fill is red, and the high- $Z$ hohlraum wall material is cyan. The window is very thin initially so only the green at the tip of the window is easily visible, where the upper zones of the window are fanned out to match the wall mesh. The plastic liner is also fairly thin and is somewhat difficult to discern at this initial time. It is a U-shaped region around the bottom and sides of the LEH cusp. The gas fill helps to hold back the initial expansion inside the hohlraum, and the plastic liner delays flow of 
high- $Z$ material into the LEH. For both early- and late-time simulations, accuracy is especially important in modeling the laser deposition and x-ray generation at the hohlraum wall. Fine initial mesh spacing in the direction normal to the wall is thus required at the inner hohlraum surface.

Figure 10 shows the hohlraum expansion at 1, 5, 10, 15, 20, 25, and $30 \mathrm{~ns}$. In this figure, the scale on the $x$ - and $z$-axes is held constant. At $1 \mathrm{~ns}$, the window has been heated and is expanding outward. At $5 \mathrm{~ns}$, the plastic liner has started to fill part of the LEH. At $10 \mathrm{~ns}$, the liner has been compressed between the high- $\mathrm{Z}$ wall material and the gas fill. Until the laser shuts off at $11 \mathrm{~ns}$, the LEH is sufficient free of high-Z material to allow the laser light to enter the hohlraum. At $15 \mathrm{~ns}$, the high- $Z$ material of the hohlraum wall has reached the axis at the LEH. At this time, the relatively low-mass window and plastic liner have expanded to very low densities and occupy a significant fraction of the mesh volume. At $20 \mathrm{~ns}$, the plasma from the hohlraum walls has compressed the $\mathrm{He}-\mathrm{H}$ gas fill to two small regions near the $z$ axis, with some He-H having escaped out the LEH's. At $30 \mathrm{~ns}$, the mesh has expanded to a size many times that of the original mesh.

Figure 11 shows the $\mathrm{x}$-component of the velocity (moving away from the $z$ axis) and the density at $30 \mathrm{~ns}$ on a somewhat expanded scale. Green lines indicate the material boundaries, which correspond to those shown in Fig. 10. The plastic liner is moving way from the $z$-axis with velocities exceeding $5 \mathrm{~cm} / \mu \mathrm{s}$. The maximum density of the high-Z hohlraum wall at this time is less than one-third its initial density. The high-density portion of the wall is red in the density plot (bottom plot in Fig. 11) and is moving away from the $z$-axis with a velocity of about $1.5 \mathrm{~cm} / \mu \mathrm{s}$ (top plot in Fig. 11). The gas fill, plastic liner and material ablated from the inside of the hohlraum are escaping out of the LEH with a large velocity $(\sim 40 \mathrm{~cm} / \mu \mathrm{s})$ primarily along the $z$-axis. However, the majority of the hohlraum mass is moving primarily away from the $z$-axis. The width of the hohlraum wall away from the equator is somewhat increased because zones initially in the wall are being pulled out during relaxation. This loss of wall resolution can be 
reduced. For example, feathering the initial wall zoning to have thinner zones on the outside of the hohlraum would make it easier for the code to maintain accurate density profiles during mesh relaxation. The outer wall zones would not have to be nearly as thin as the inner wall zones.

This simulation is continued to approximately $80 \mathrm{~ns}$ and then the results are postprocessed. The density at $78 \mathrm{~ns}$ is shown in Fig. 12 along with a sketch of the original hohlraum location. The debris is accelerated until it reaches a terminal velocity of approximately $5 \mathrm{~cm} / \mu \mathrm{s}$ or $50 \mathrm{~km} / \mathrm{s}$. By looking at the time history of the magnitude and direction of the velocity, we can determine when a ballistic assumption is valid to determine the location the debris will strike the chamber. We find that the blow-off is far from isotropic with roughly ten times the material going perpendicular to the hohlraum axis as compared to streaming out the LEH. Thus only fraction of the expanding hohlraum debris will be deposited on the debris shields, which bodes well for operational considerations. In addition, the debris can interact with surrounding diagnostic components. The amount of debris energy incident on a component can be as great as the $\mathrm{x}$-ray energy incident on the object. A major difference is that the duration of the impact by debris is generally a factor of 10 longer than the $\mathrm{x}$-ray impact. As a result, spall and fragmentation are less likely to occur with debris loading than with x-ray loading. However, the debris can change of the direction of expanding shrapnel fragments produced by x-ray loading. The acceleration can be large enough to change the direction of the fragments and the location where they strike the chamber wall.

Experiments are in progress that will serve to benchmark and optimize these simulation results and techniques for configurations that are attainable on today's lasers. In addition, calculations such as these are being used for the design of the next generation of laser systems. 


\section{Conclusions}

We have studied the spatial distribution of $\mathrm{x}$ rays emitted from NIF hohlraums using the radiation hydrodynamic code LASNEX. We show that the radiation is anisotropic with a minimum on axis for this vacuum hohlraum simulation. For this hohlraum, the x-ray fluence has a broad maximum that occurs at an angle around $45^{\circ}$, where there is a very good view of the inside hohlraum wall, and the fluence at $90^{\circ}$ is down by $30 \%$ from the peak. A hohlraum wall thicker than $20 \mu \mathrm{m}$ would reduce the $\mathrm{x}$ radiation at $90^{\circ}$. The duration (6 $\mathrm{ns} \mathrm{FWHM}$ ) of the x-ray emission is approximately twice that of the duration ( $3 \mathrm{~ns}$ FWHM) of the driving laser. The $\mathrm{x}$ rays calculated for $90^{\circ}$ (primary contribution is emission from the outside of the hohlraum wall) are relatively low energy with $88 \%$ of the emission for energies of $500 \mathrm{eV}$ and below with only $2 \%$ above $1 \mathrm{keV}$. For viewing angles that can see inside the hohlraum through the LEH, hotter spectrums are obtained. There is evidence that the LEH closes to $\mathrm{x}$ rays approximately $15 \mathrm{~ns}$ after the peak of the laser pulse.

The new ALE grid relaxation algorithm in the radiation hydrodynamic code HYDRA enables late-time simulations of a hohlraum, including the outward expansion of the hohlraum wall. To avoid having different parts of the outer mesh boundary interact, we adjusted the code parameters to control relaxation the mesh as needed. The late-time calculation of hohlraum expansion gives the density and velocity of the associated debris wind. The majority of the hohlraum mass expands away from the hohlraum axis with a terminal velocity of approximately $50 \mathrm{~km} / \mathrm{s}$. The amount of debris expected to be deposited on the debris shields is approximately a factor of 10 less than if the expansion had been isotropic. Calculations of this type will be the basis for future studies that include debris wind effects on chamber components.

Experiments for NIF and LMJ must be designed to achieve the required physics goal while minimizing their impact on the target chamber. In particular, the amount of debris and shrapnel incident on the debris shields must be controlled. Simulations 
demonstrate how changes to target designs could reduce debris damage without significantly affecting a given experiment. For example, increasing the hohlraum wall thickness can reduce the X-ray loading on components, which can reduces shrapnel generation at the cost of increasing the amount of debris. When DDS's are in use, this trade-off can be beneficial. The lifetime of DDS's is primarily a function of the number of large and fast shrapnel fragments and not the amount of debris loading. Late-time simulations of targets will aid in determining the optimum target design parameters and optimum placement of diagnostic components.

\section{Acknowledgment}

This work was performed under the auspices of the U.S. Department of Energy by the University of California, Lawrence Livermore National Laboratory Under Contract No. W-7405-Eng-48.

\section{References}

1. HAAN, S. W., et al., Phys. Plasmas 2 (1995) 2480.

2. SUTER, L. J., et al., Phys. Rev. Lett. 73 (1994) 2328.

3. DITTRICH, T. R., et al., Physics of Plasmas 6 (1999) 2164.

4. MARINAK, M. M., et al., Physics of Plasmas 8 (2001) 2275.

5. ANDERSON, A. T., MANAGAN, R. A., TOBIN, M. T., and PETERSON, P. F., Fusion Technology 30 (1996) 425.

6. PETERSON, R. R., HAYNES, D. A., GOLOVKIN, I., and MOSES, G. A., Phys. of Plasmas 9 (2002) 2287.

7. PAISNER, J. A., BOYES, J. D., KUMPAN, S. A., LOWDERMILK, W. H., and SOREM, M., Laser Focus World 30 (1994) 75.

8. JOLAS, A. et al., IFSA99, Bordeaux, France 1999, (Elsevier, Paris, 2000), pp 6873.

9. ZIMMERMAN, G. B. and KRUER, W. L., Comments Plasma Phys., 2 (1975) 51. 
10. HARTE, J. A., The ICF Quarterly Report $4^{\text {th }}$ Quarter 1996, Lawrence Livermore National Laboratory Report UCRL-LR-105821-96-4.

11. KAUFFMANN, R. et al., Phys Rev. Lett. 73 (1994) 2320.

12. NISHIMURA, H., et al., $14^{\text {th }}$ International Conference on Plasma Physics and Controlled Nuclear Fusion Research, Würzburg, Germany, 1992 (International Atomic Energy Agency, Vienna, 1993), Vol. 3 p. 97.

13. ANDRÉ, M., et al., Laser and Particle Beams 12 (1994) 329.

14. National Academy of Science Review of the Department of Energy's Inertial Confinement Fusion Program, Final Report (National Academy Press, Washington, DC, 1990).

15. EDER, D. C., ANDERSON, A. T., BRAUM, D. G., and TOBIN, M. T., SPIE High-Power Laser Ablation III, Vol. 4065 (2000) 86. 


\section{Figure Captions}

FIG. 1. Sketch of a NIF-scale hohlraum showing the small artificial cusps added to the LEH's in the simulations to obtain high resolution zoning for wall material that faces axis. We also showing the three viewing angles $\left(0,45\right.$, and $\left.90^{\circ}\right)$ used in Figs. 4 and 6 .

FIG. 2. The "ignition type" laser pulse shape used in the LASNEX calculation of x-ray emission.

FIG. 3. Images of the calculated x-ray emission (integrated over energy) from the hohlraum viewed at an angle of $45^{\circ}$ from the hohlraum axis. Figure 3a is at a time of 19.5 ns and Fig. $3 \mathrm{~b}$ is at a time of $45.5 \mathrm{~ns}$. The color bar gives the logarithm of the $\mathrm{x}$-ray emission.

FIG. 4. The time dependence of the $\mathrm{x}$-ray emission is given for three viewing angles $(0$, 45 , and $90^{\circ}$ ).

FIG. 5. The time integrated $\mathrm{x}$-ray emission as a function of viewing angle.

FIG. 6. The time-integrated, normalized energy spectrum using 10 energy bins for three viewing angles $\left(0,45\right.$, and $\left.90^{\circ}\right)$.

FIG. 7. The calculated electron temperature for a 0.6 -scale NIF gas-filled hohlraum from 0 to $8 \mathrm{~ns}$. Images on the right are enlarged views around the LEH cusp, giving more detailed temperature and mesh information. 
FIG. 8. The calculated electron temperature for a 0.6-scale NIF gas-filled hohlraum from 12 to $30 \mathrm{~ns}$. Images on the right are enlarged views of the LEH cusp, showing how the area fills at 12 and 20 ns.

FIG. 9. Enlarged view of the region around the left LEH, showing the different materials. The thin polyimid window is green, the plastic liner near the LEH is blue, the gas fill is red, and the high- $Z$ hohlraum wall is cyan.

FIG. 10. The expansion of the 0.6-scale NIF gas-filled hohlraum is shown from 0 to $30 \mathrm{~ns}$. The polyimid window is green, the plastic liner is blue, the gas fill is red, and the high- $Z$ hohlraum wall is cyan.

FIG. 11. The x-component of the velocity (top plot) and the density (bottom plot) at $30 \mathrm{~ns}$. Note that all zones with velocities away from the axis greater than $6 \mathrm{~cm} / \mu \mathrm{s}$ up to a maximum of $47 \mathrm{~cm} / \mu \mathrm{s}$ are colored red to focus on the slower velocity regions. Green lines indicate material boundaries, which correspond to those shown in different colors in Fig. 10 .

FIG. 12. The density distribution of the hohlraum at $78 \mathrm{~ns}$ with a sketch giving the original location. 


$$
90^{\circ}
$$

$45^{\circ}$

$$
45^{\circ}
$$

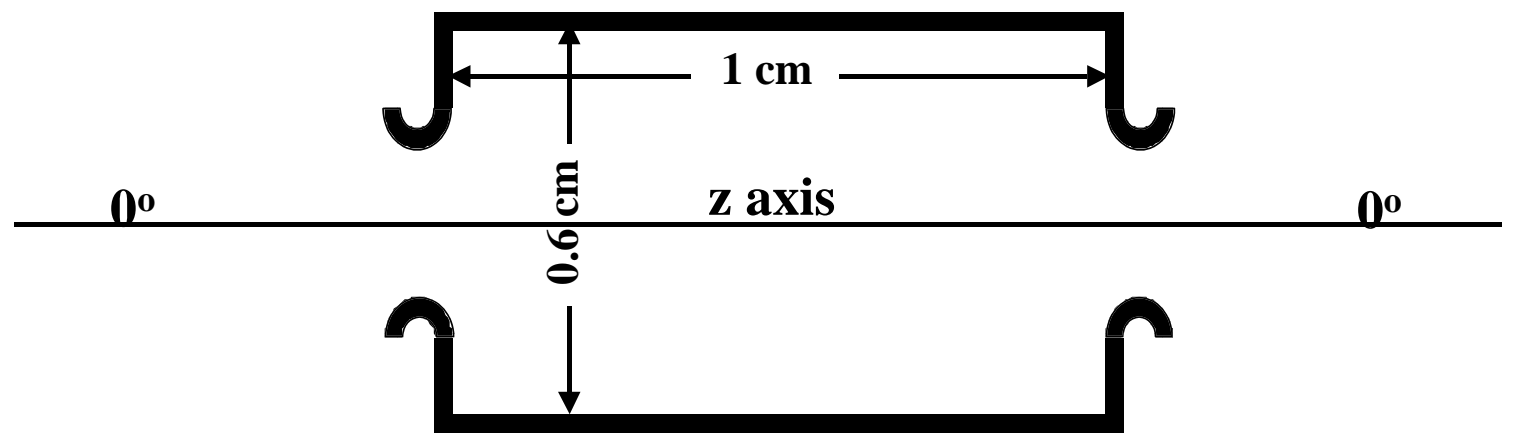

$45^{\circ}$

$45^{\circ}$

$90^{\circ}$

Figure 1. 


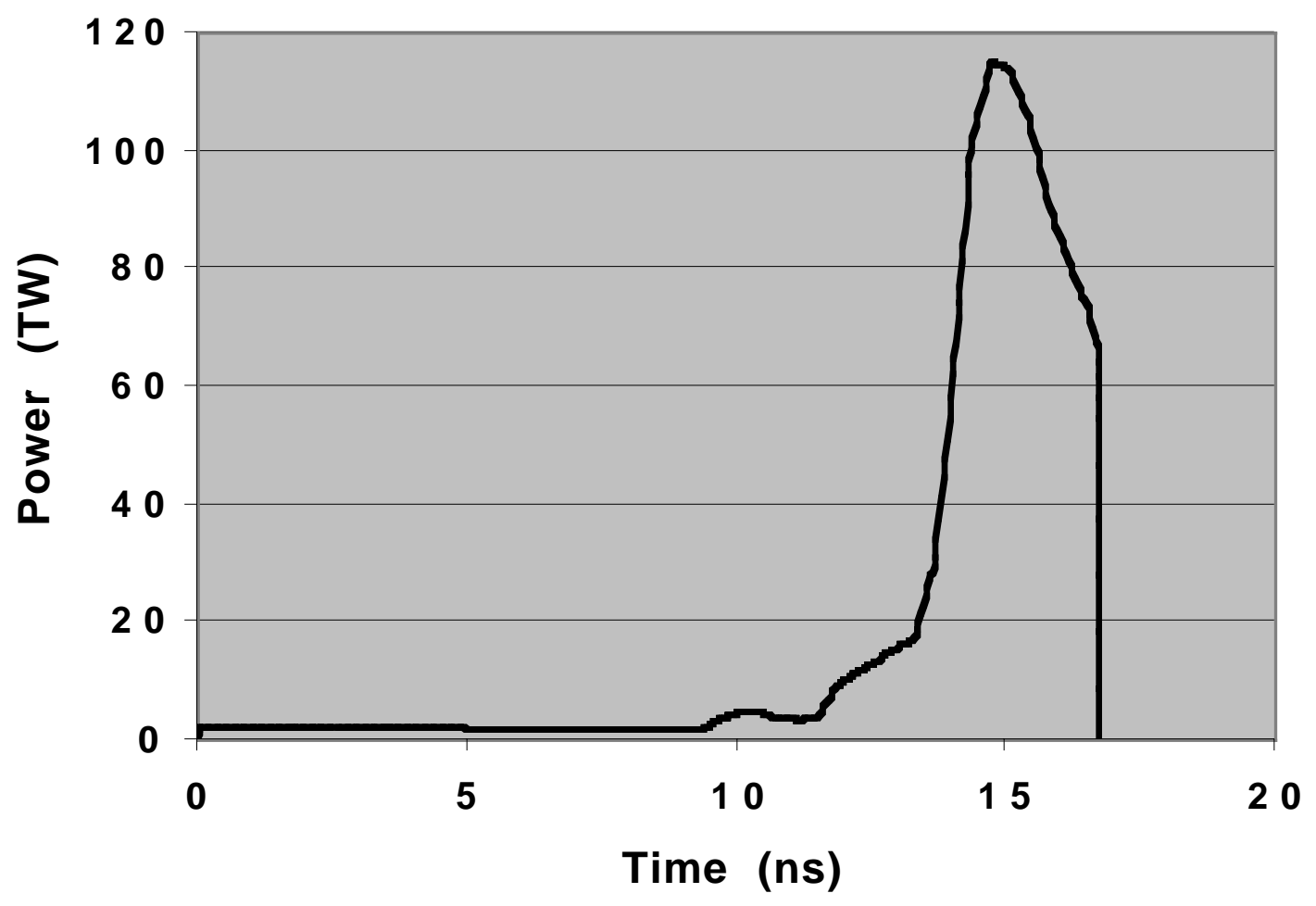

Figure 2. 

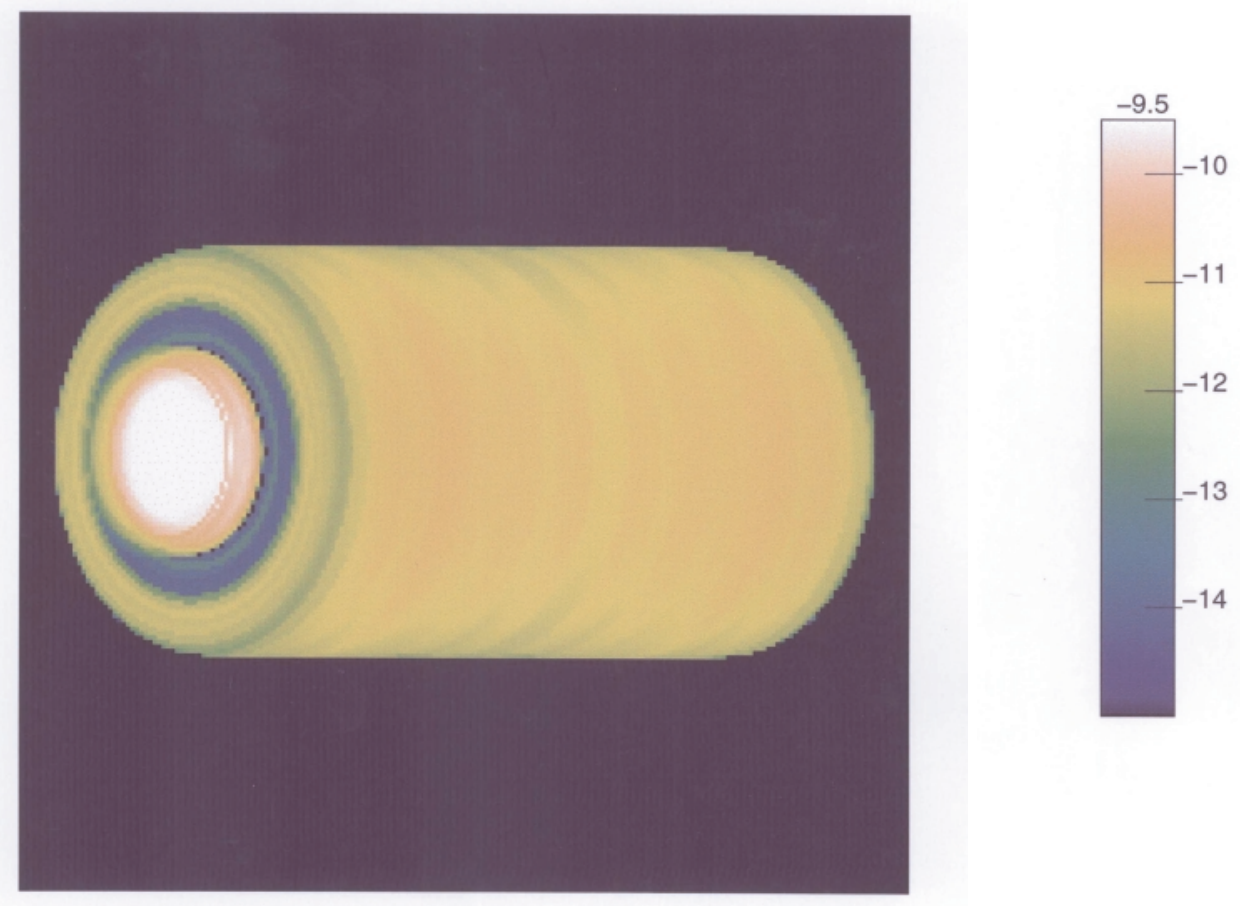

Figure $3 a$.
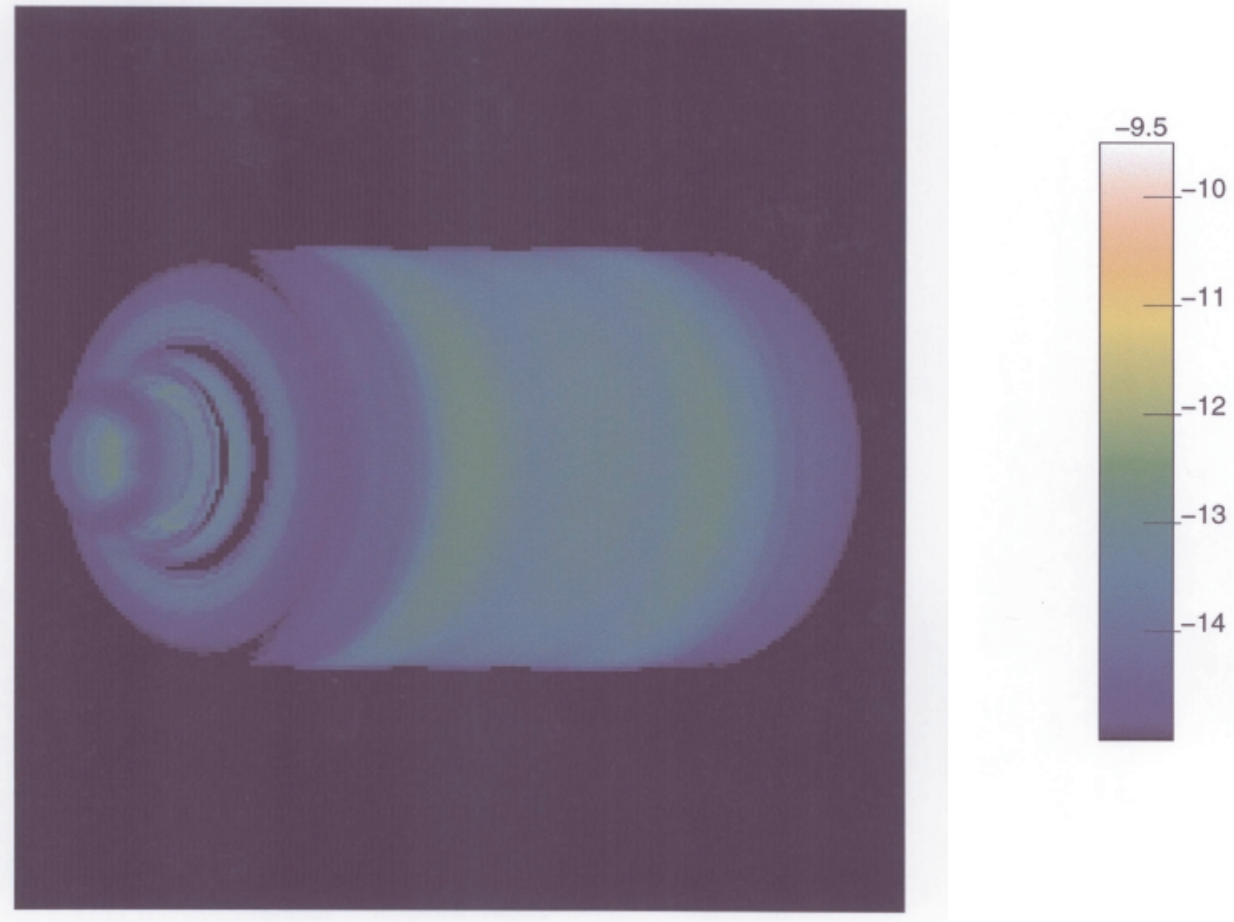

Figure 3b. 


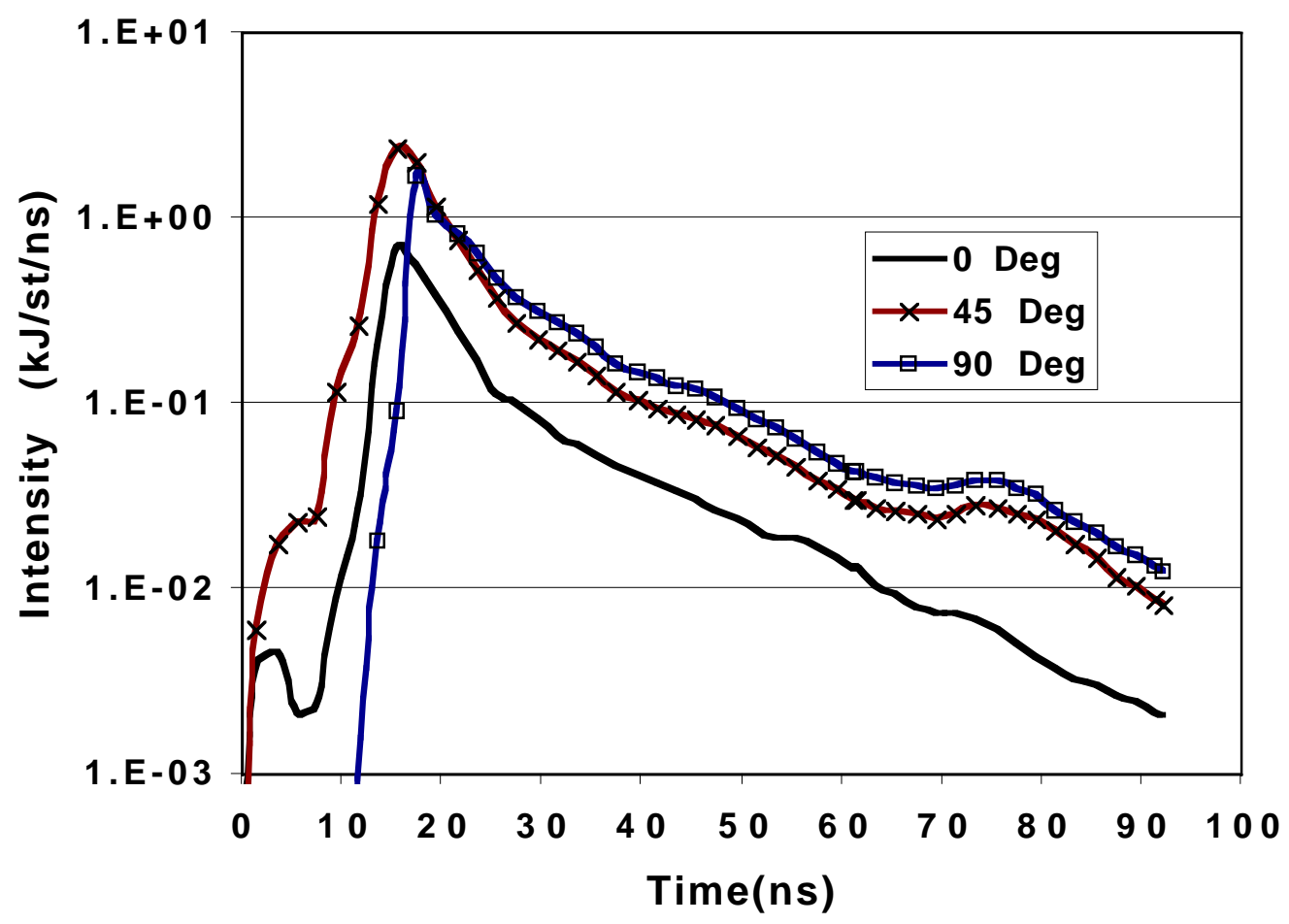

Figure 4. 


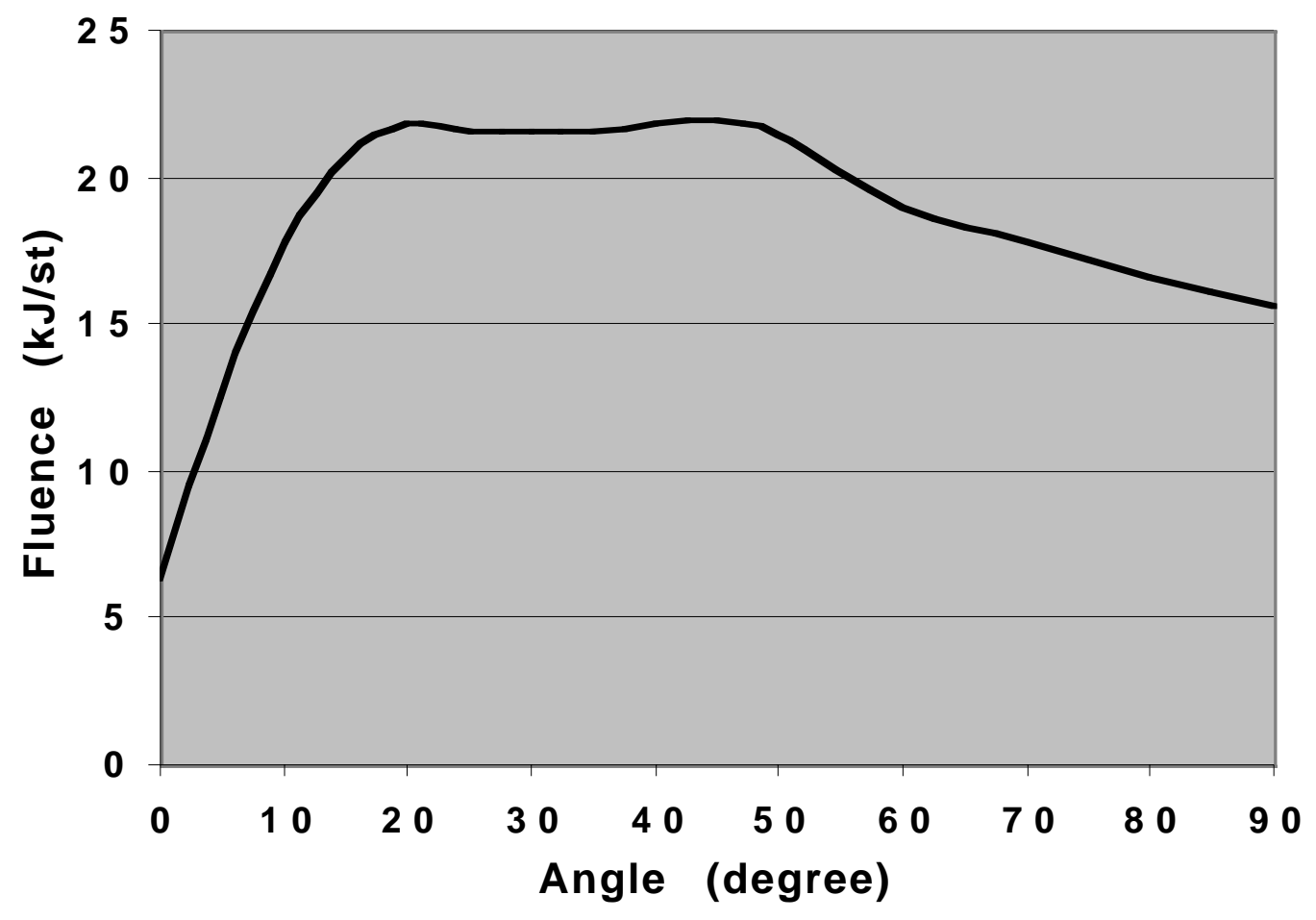

Figure 5. 


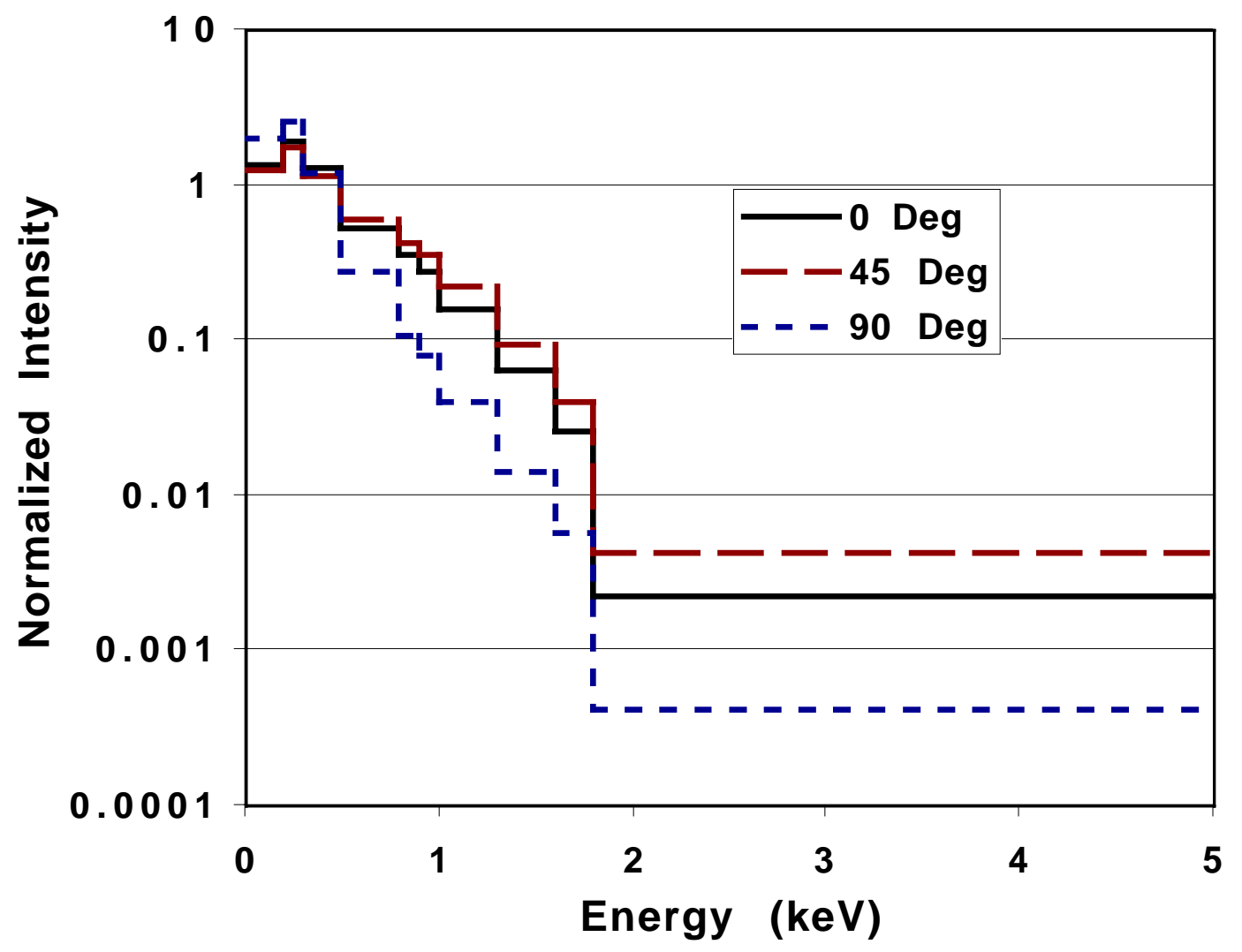

Figure 6. 

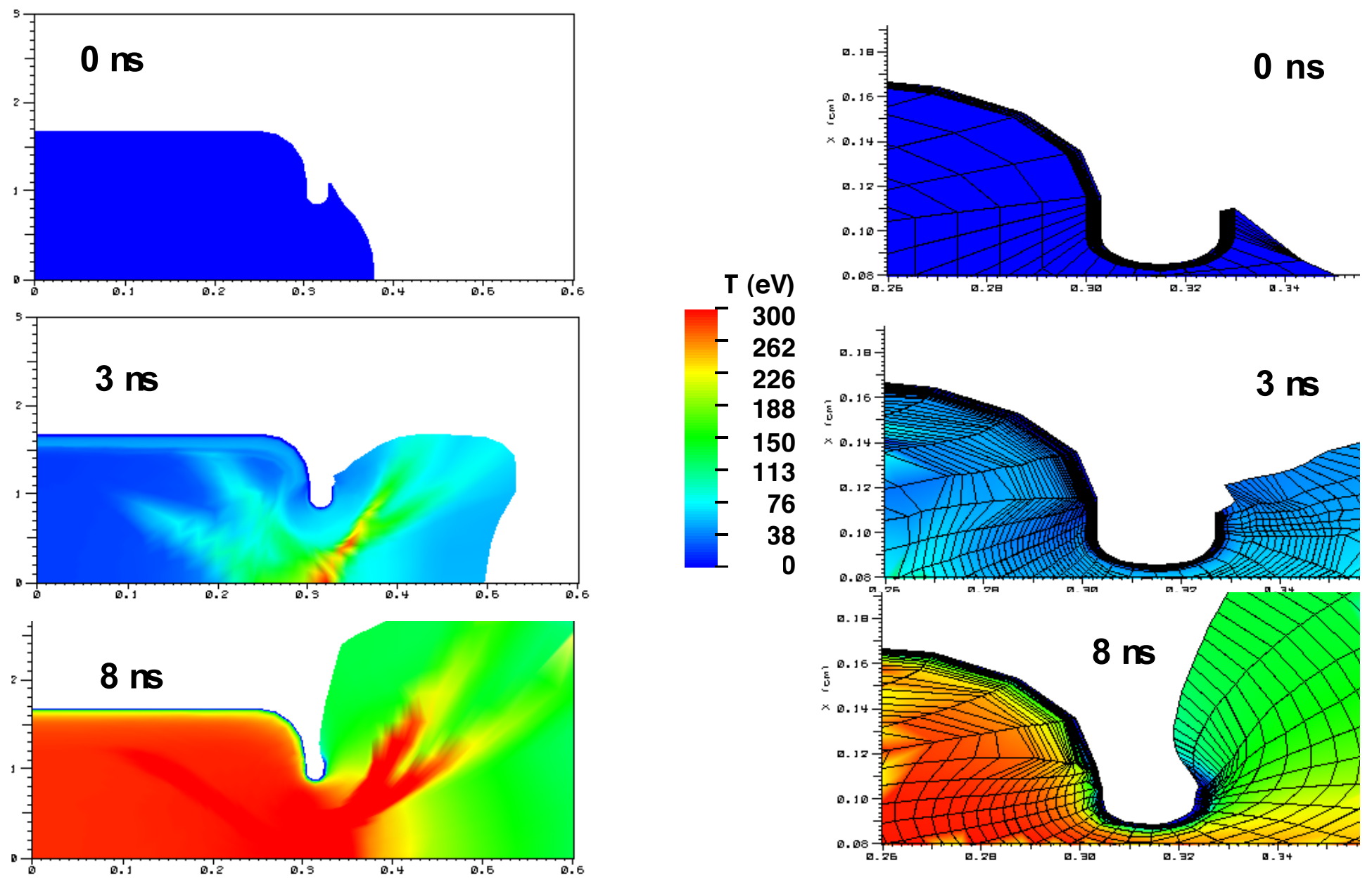

Figure 7. 


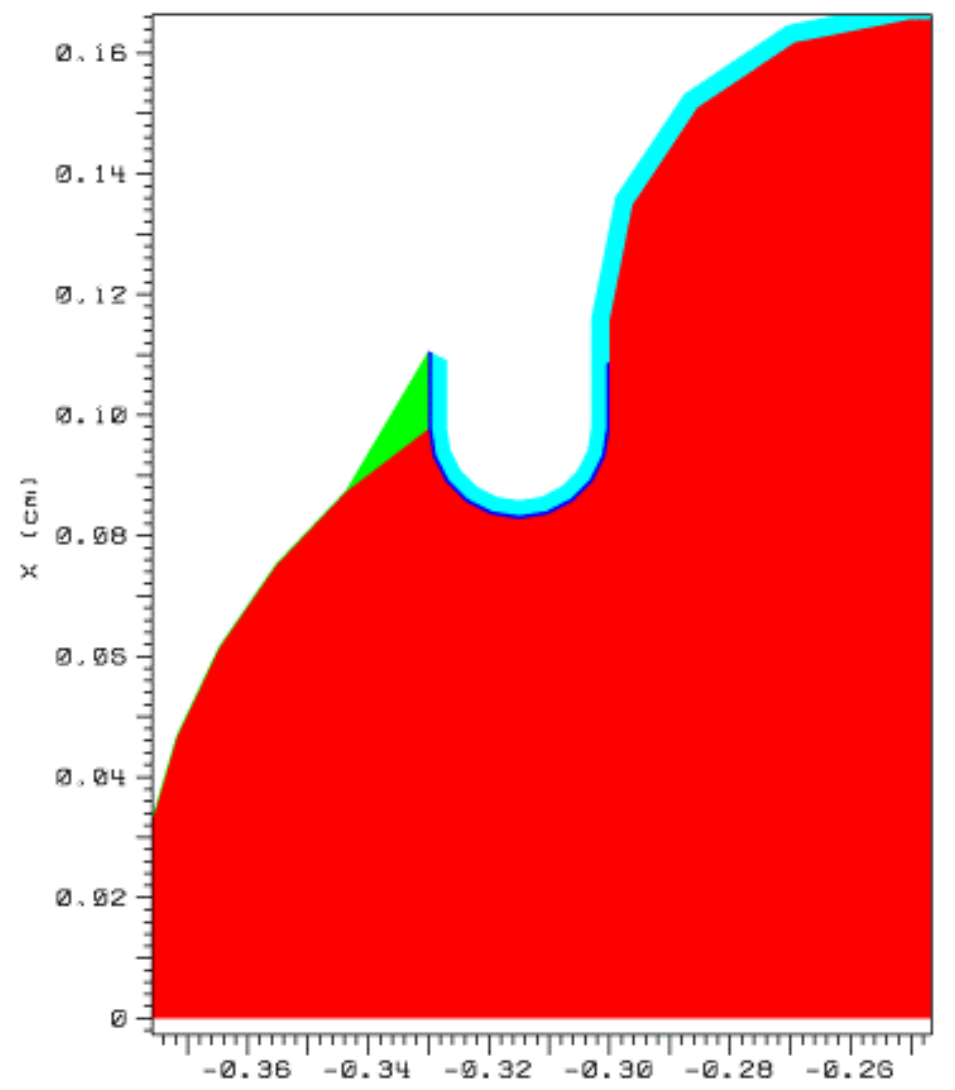

Figure 8. 


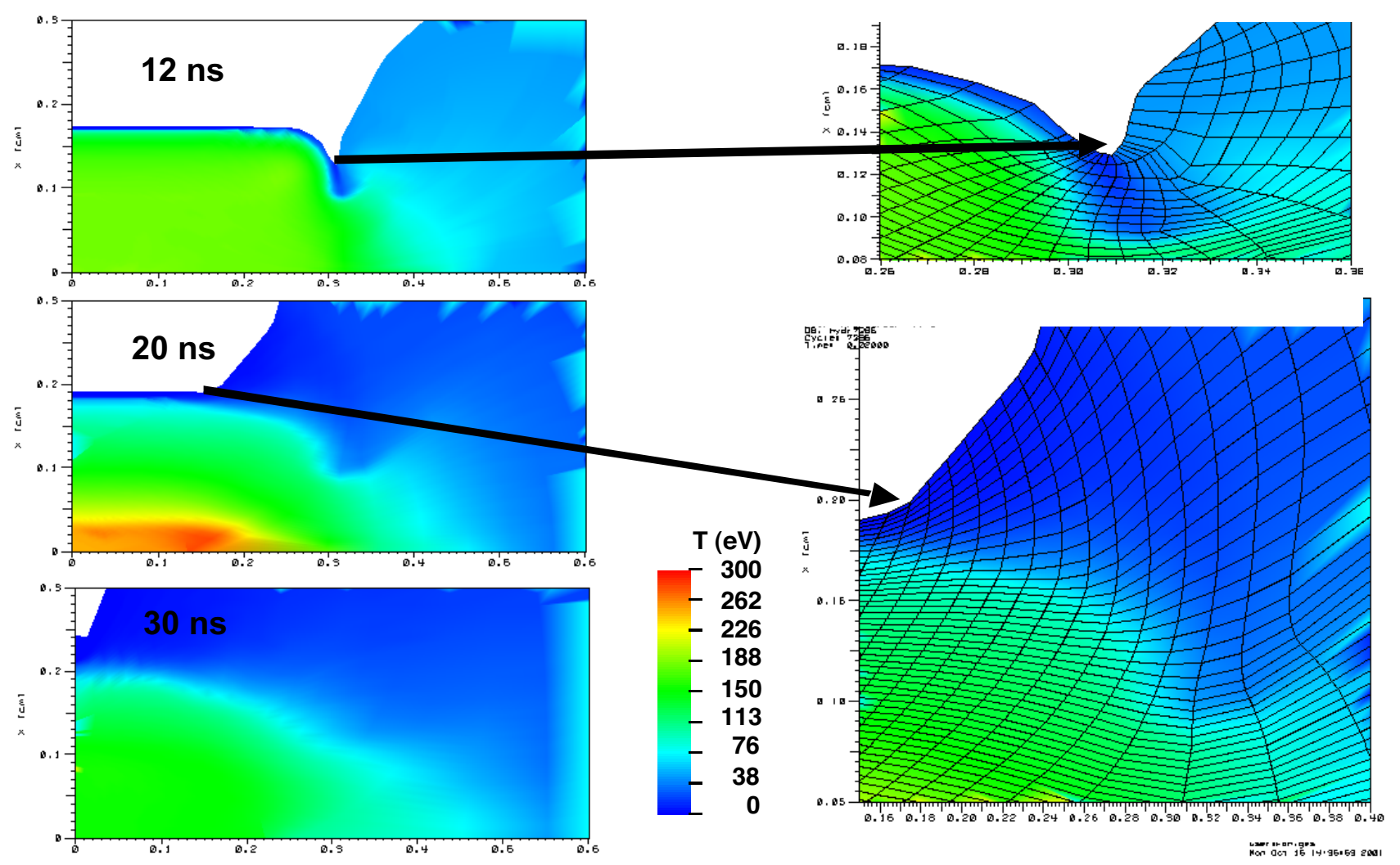

Figure 9. 

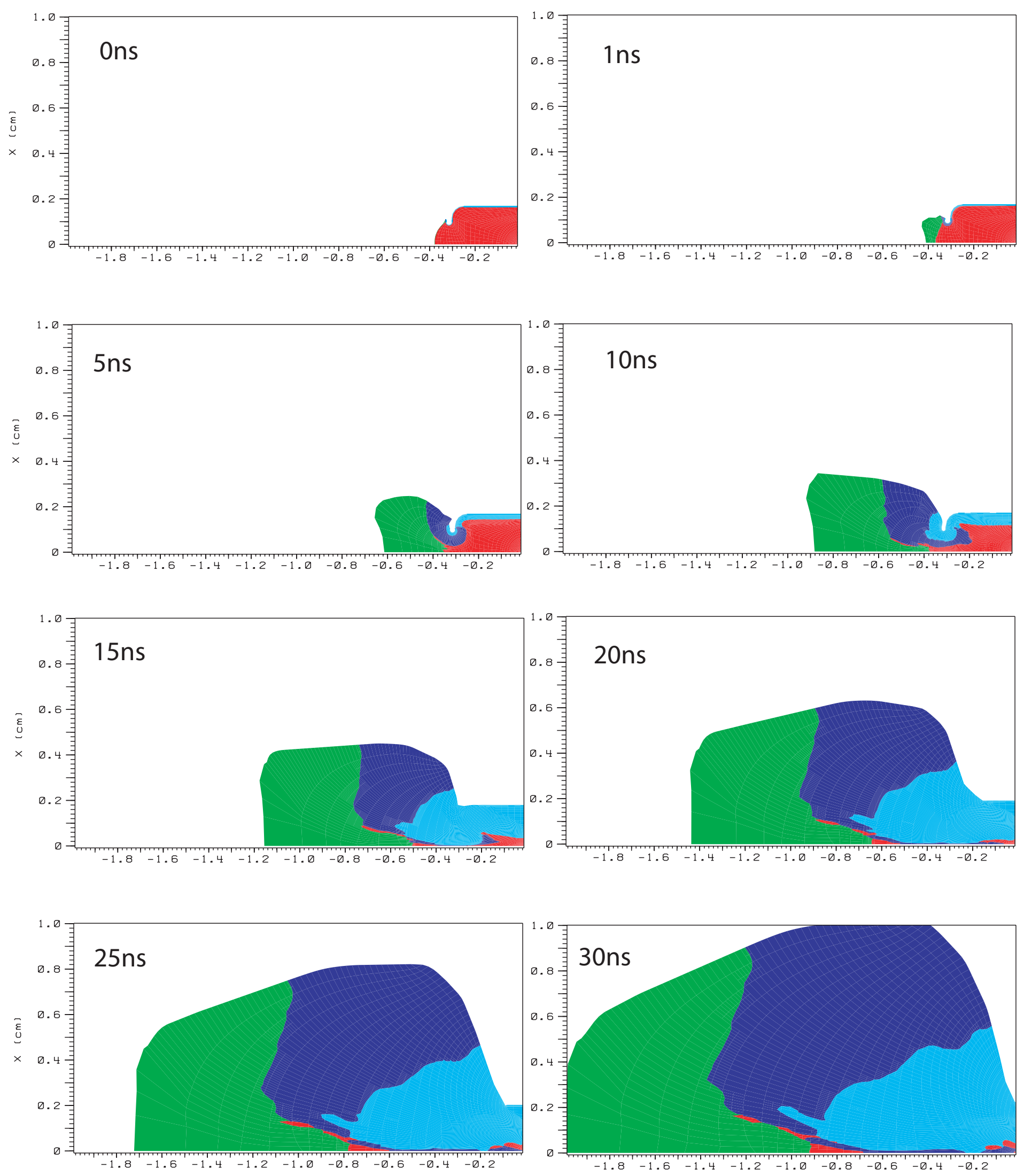

Figure 10. 

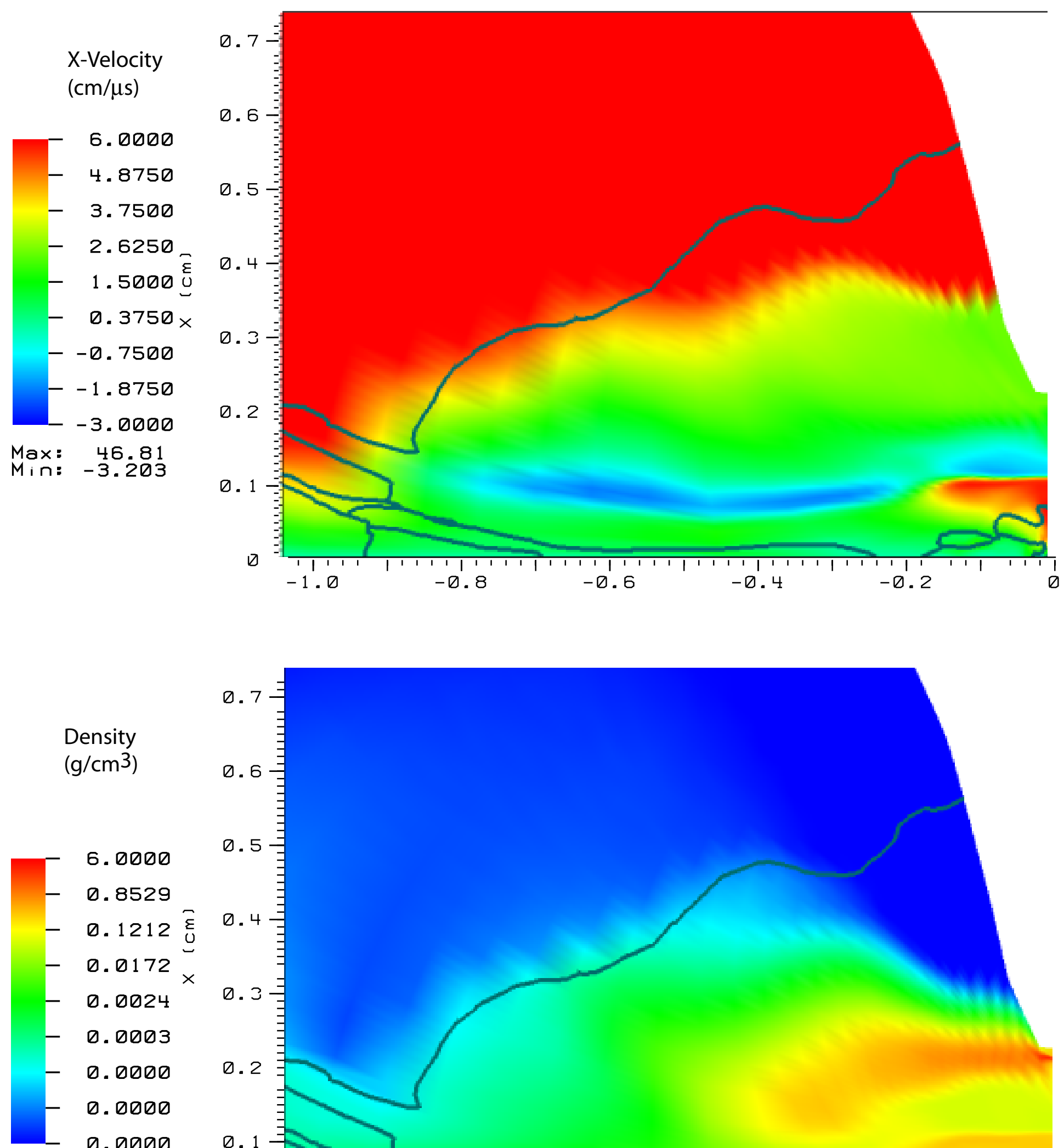

6. 0000

Density

(g/cm3)

Max:

๑. 8529

-0.1212 E

$-0.0172 \times$

- 0.0024

- 0.0003

- 0.0000

0.0000

0.0000

5.405

๑. อDอ

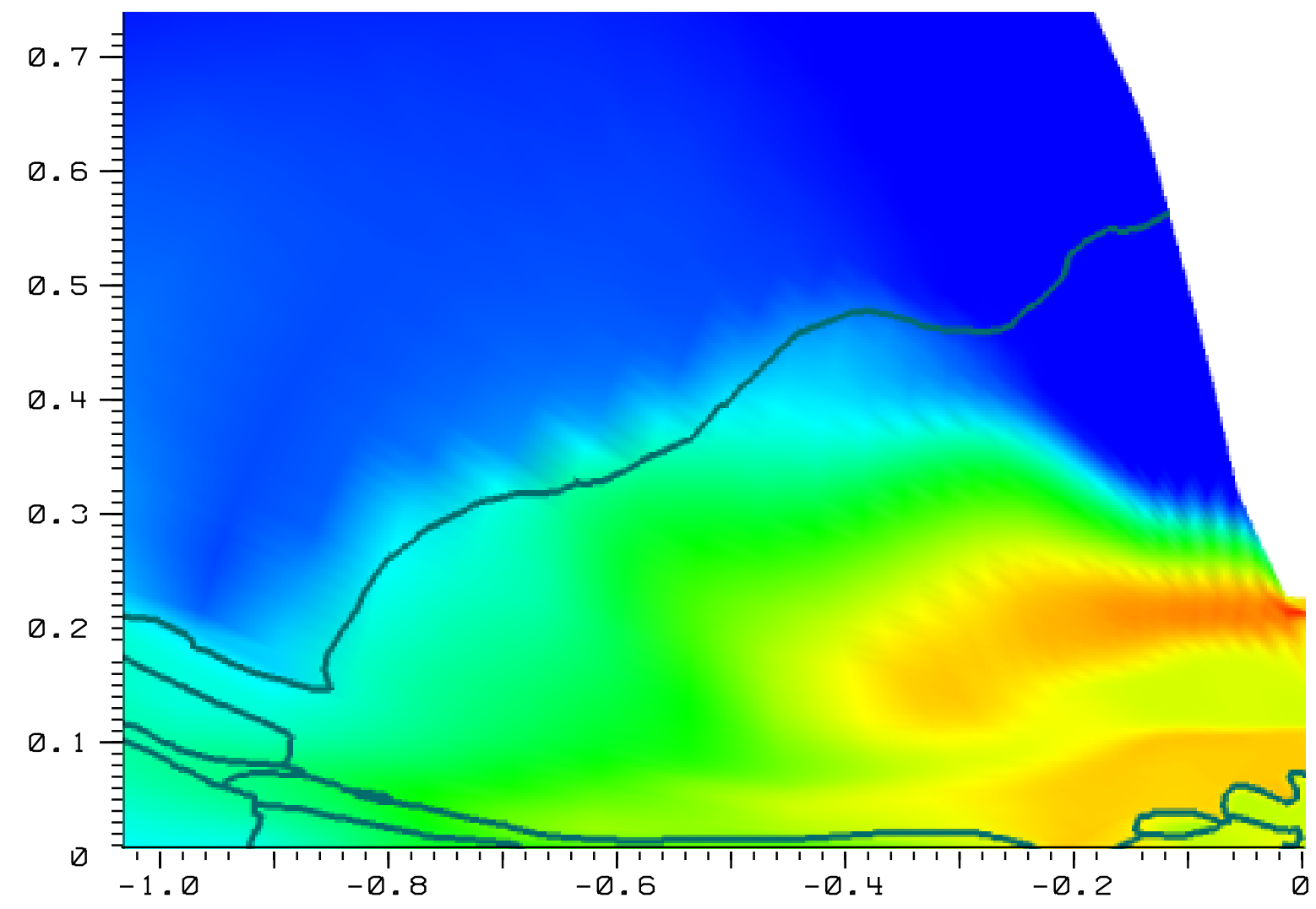

Figure 11. 


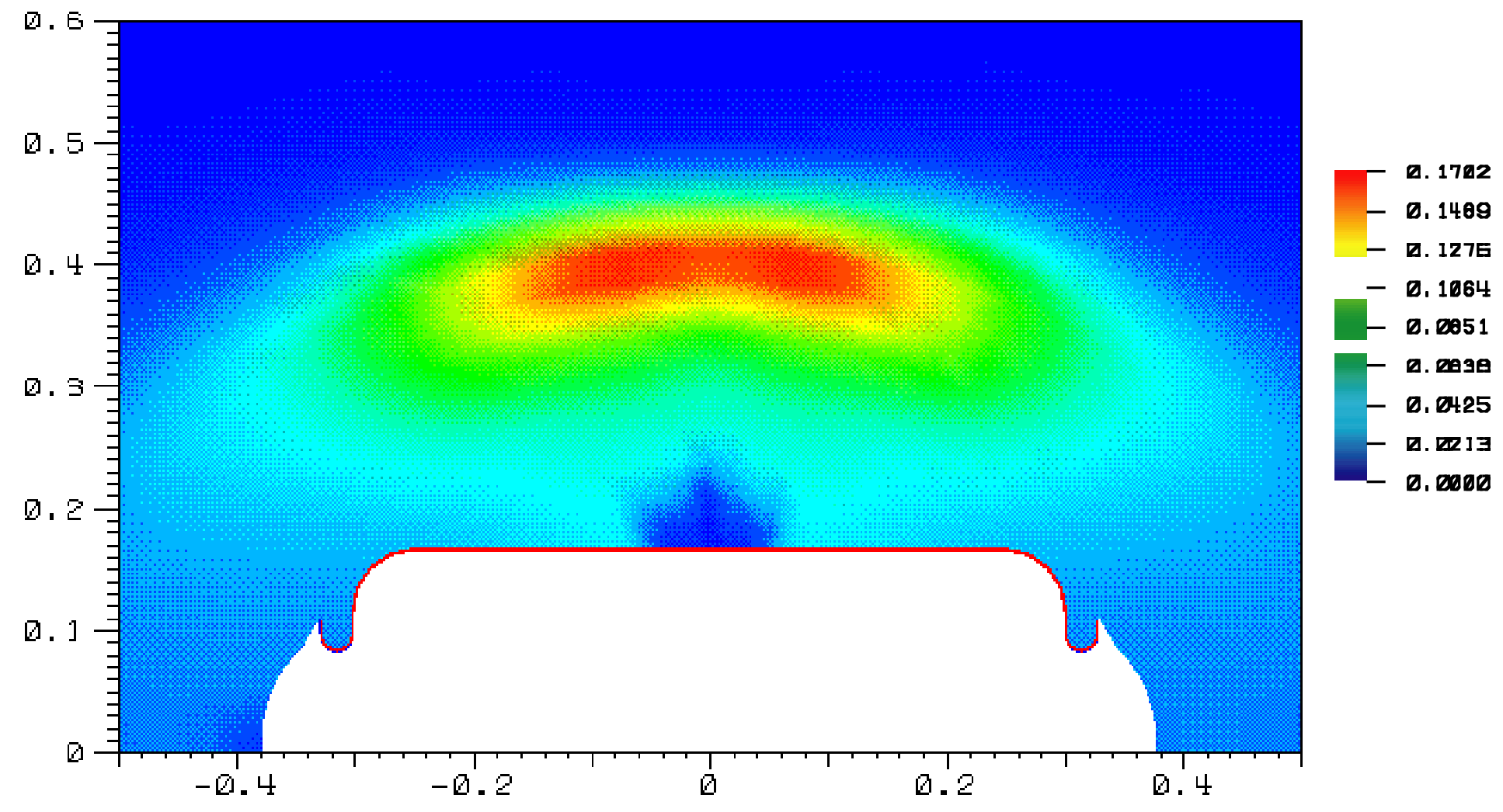

Figure 12. 